\title{
Mechanism for the Optimal Location of a Business as a Lever for the Development of the Economic Strength and Resilience of a City
}

\author{
Stella Manika *D, Konstantinos Karalidis and Aspa Gospodini
}

check for updates

Citation: Manika, S.; Karalidis, K.; Gospodini, A. Mechanism for the Optimal Location of a Business as a Lever for the Development of the Economic Strength and Resilience of a City. Urban Sci. 2021, 5, 70. https:// doi.org/10.3390/urbansci5040070

Academic Editor: Tan Yigitcanlar

Received: 19 July 2021

Accepted: 17 September 2021

Published: 23 September 2021

Publisher's Note: MDPI stays neutral with regard to jurisdictional claims in published maps and institutional affiliations.

Copyright: (c) 2021 by the authors. Licensee MDPI, Basel, Switzerland. This article is an open access article distributed under the terms and conditions of the Creative Commons Attribution (CC BY) license (https:/ / creativecommons.org/licenses/by/ $4.0 /)$.
Department of Planning and Regional Development, University of Thessaly, 38334 Volos, Greece; kkaralidis13@gmail.com (K.K.); gospod@uth.gr (A.G.)

* Correspondence: smanika@uth.gr

\begin{abstract}
Today, the location of a business is more important than ever, as it contributes to its consolidation in the market and, in parallel, to the economic development of a city. Over the years, the theories about the optimal location of a business have undergone various changes, both financial and spatial. On the other hand, economic geography, as a discipline that studies the distribution of economic activities as well as the interactions between them, is also an important tool for the analysis of urban/spatial and business processes. This paper finds the optimal locations of economic activities through the combination of theories of economic geography and spatial analysis, for the sake of reducing urban shrinkage and increasing the resilience of businesses and cities. The analysis of this paper proved that the areas that are most exposed to urban shrinkage are the least central areas. Urban shopping centers, despite the large percentage of closed stores, continue due to their centrality to attracting more new businesses. The calculation of the optimal location of the economic activity showed that the optimal location depends on the financial sector itself but also on the economic activities that open or close over time in this region. In this way, an answer is sought regarding the way in which each region and its economic identity can influence a city's future development and resilience. Thus, through this analysis, cities are able to control and strengthen their economic landscapes, vulnerable as they are in difficult times, and to implement policies in specific urban units, with a view to the prosperity of their economic activities.
\end{abstract}

Keywords: resilience of businesses; urban shrinkage; urban resilience; urban planning; spatial analysis; economic geography; urban policies

\section{Introduction}

Economic geography in modern times is not solely about the effects of economic activity on the geographical sphere: it is also about the effects of the geographical sphere causes on economic activity. The combination of economic geography principles and optimal business location techniques can lead to a new perspective on urban analysis as concerns the economic identity of the city as well as the reduction in urban shrinkage and can contribute to the optimal and more effective analysis and identification of the characteristics that lead to a city's resilient character.

More specifically, the theoretical framework of the article is based on three dominant concepts. The first concept is related to urban shrinkage. Urban shrinkage is defined as the phenomenon that can affect, i.e., regions, cities, or areas that are facing population reductions and, in parallel, intense economic and/or social transformations due to financial or other crises. These areas typically include an abundance of abandoned residential units and vacant shops [1]. In this paper, the authors capture the role of the principles of economic geography and, more specifically, of optimal business location techniques in reversing the phenomenon of urban shrinkage and leading to urban resilience. Thus, the third basic concept of the article, that of urban resilience, is based on the recognition of 
the city as a highly complex [2] adaptive system [3], in which the malleable meaning of resilience [4] can help cities adapt to new economic conditions. This article examines urban resilience to the effects of the economic crisis, and, more specifically, urban shrinkage, and how it is perceived within the urban fabric.

For these reasons, this paper aims to analyze theories regarding the optimal location of businesses in the urban fabric, and to use spatial analysis to identify areas within the city of Volos (a typical medium-sized Greek city facing urban shrinkage signs) in which a business is more likely to grow economically. These areas can act as local levers for the development of the economic strength and resilience of the city of Volos.

\section{Literature Review}

The literature review reveals the dominant research and analysis method focused on optimal location, via qualitative analysis, and the relevant dominant bibliographic trends via quantitative analysis and graphs.

\subsection{Business Location Planning Methods}

The study of BLP (business location planning) problems has been widely analyzed from different angles over the years. These analyzes more often concern geographic locations, qualities (stars and prices), and social influence [5] or the behavior of social network users [6].

- $\quad$ Distance-based: The RNN (reverse nearest neighbor) has been addressed in several works. This method aims to find the location with the largest influence based on the number of RNN users in a specific area. These users are considered to be influenced by the location $[7,8]$.

- Distance and quality-based: These methods are based on the quality attributes of the location, such as cost and rating. To solve the BLP problem, Shi et al. (2014) [9] found the location where the influence is maximized, and the cost is minimized. The influence was measured based on the existing spatial objects, whereas the cost was measured by the payment quality of the existing objects.

- Distance and social influence-based: As indicated in the above section, with the prevalence of social network marketing, it is necessary to consider the social influence in the BLP problem. Hung et al. (2016) [10] derived the RNN users of a location in a social network and calculated the spread of influence of the RNN users over the social network. The location with the largest influence spread was selected as the best location. The limitation of the work of Hung et al. [10] is that the RNN users may have a weak influence and may not be willing to promote the location. Thus, Zeng et al. (2020) [5] addressed the BLP problem by exploiting influence maximization techniques to promote each candidate location actively, thereby guaranteeing the achievement of the maximum spread of influence for each candidate location [6].

Due to technological advancement, most recent research has focused on data mining from platforms as a means of gaining valuable insights to better support strategic and operational business decisions and algorithms, so as to find the best place to start a business, where there is high demand, by means of web search engines [11,12].

The Huff model has been widely used in location-based business analysis to delineate a trade area containing a store's potential customers. Calibrating the Huff model and its extensions requires empirical location visit data. Many studies rely on labor-intensive surveys. With the increasing availability of mobile devices, users of location-based platforms share rich multimedia information about their locations at a fine spatio-temporal resolution, which offers opportunities for business intelligence. The original Huff model and its subsequent extensions have been widely used to model a brand or a store's trade area and to predict customer visit probability, but they are largely static.

Recent research by McKenzie and Adams (2017) [13] demonstrated that thematic regions can be represented dynamically using place-type specific temporal patterns. Customers have different temporal visit preferences for different types of stores. A dynamic 
model is thus required to better capture the spatio-temporal characteristics of customers' store visit behaviors [14] Finally, some important research that has been reviewed for this study is shown in Table 1. These studies have proven that location selection or optical location methods present a variety of applications related to the functions of urban space. In any case, they are characterized as very efficient in terms of the description and better understanding of urban phenomena, especially economic phenomena and their consequences, which is why they were adopted in this article.

Table 1. Research focus-analysis method.

\begin{tabular}{|c|c|c|c|}
\hline Authors Name & Year & Research Focus & Analysis Method \\
\hline Liu [15] & 2012 & \multirow{2}{*}{$\begin{array}{l}\text { Location selection for a new supermarket } \\
\text { Predict the service area and potential customer } \\
\text { pool }\end{array}$} & GIS and Huff model \\
\hline Pan et al. [16] & 2013 & & Network distance and Huff model \\
\hline Grohmann et al. [17] & 2016 & Huff facility location problem on networks & Metaheuristic and exact approaches \\
\hline Wang et al. [18] & 2016 & Evaluating trade areas & $\begin{array}{c}\text { Social Media Data with a Calibrated Huff } \\
\text { Model }\end{array}$ \\
\hline Liang et al. [14] & 2020 & $\begin{array}{c}\text { Calibrating the dynamic Huff model for business } \\
\text { analysis }\end{array}$ & Location-based big data \\
\hline Banerjee et al. [19] & 2020 & Optimal locations for bike-share stations & GIS-based spatial approach \\
\hline Zeng et al. [6] & 2021 & Business location planning & Novel influence diffusion model \\
\hline
\end{tabular}

\subsection{Bibliometric Analysis}

At the same time, in order to obtain a better understanding of the relevant literature and its dominant trends, a bibliometric analysis was used. The main tool of the article's analysis was the bibliometrix package (along with biblioshiny App, an R-tool described in detail by Aria and Cuccurullo [20]), which presents an interesting multitude of results in its social science [21] and urban science [22,23] applications.

The web of science was used as the source of data. The keywords that formed the basis of the search were sourced from meanings related to the business location and can be grouped into scientific fields related to management, business, economics, environmental studies, geography, urban studies, regional and urban planning, development studies, physical geography, and business finance. The period from 2010 to 2021 was chosen as the reference period because it can provide the most contemporary approaches to the term under research. Duplicates were excluded, and only papers in English were considered. A hand search was performed and led to the collection of 1819 documents (Table 2).

Table 2. Main information about data used.

\begin{tabular}{cc}
\hline Description & Results \\
\hline Main information about data & $2010: 2021$ \\
\hline Timespan & 570 \\
\hline Sources (journals, books, etc) & 1819 \\
\hline Documents & 4.78 \\
\hline Average years from publication & 15.38 \\
\hline Average citations per documents & 2.232 \\
\hline Average citations per year per doc & 80,990 \\
\hline References & 1746 \\
\hline Document types & 59 \\
\hline Article & 14 \\
\hline Article; early access & \\
\hline
\end{tabular}


Table 2. Cont.

\begin{tabular}{cc}
\hline Description & Results \\
\hline Document Contents & 3130 \\
\hline Keywords Plus (ID) & 5535 \\
\hline Author's Keywords (DE) & 4186 \\
\hline Authors & 4838 \\
\hline Authors & 299 \\
\hline Author appearances & 3887 \\
\hline Authors of single-authored documents & 311 \\
\hline Authors of multi-authored documents & 0.435 \\
\hline Authors collaboration & 2.3 \\
\hline Single-authored documents & 2.66 \\
\hline Documents per author & 2.58 \\
\hline Authors per document &
\end{tabular}

According to the graph of word growth (Figure 1) we observe the particular increase in the appearance of the concepts 'location', 'performance', 'innovation' and 'foreign direct investment' from 2018 onwards, according to the articles in our database. From 2019 onwards (as shown in Figure 2), the concept of models is also highlighted. These concepts seem to characterize the dominant clusters as they appear in the Figure 3.

\section{Word Growth}

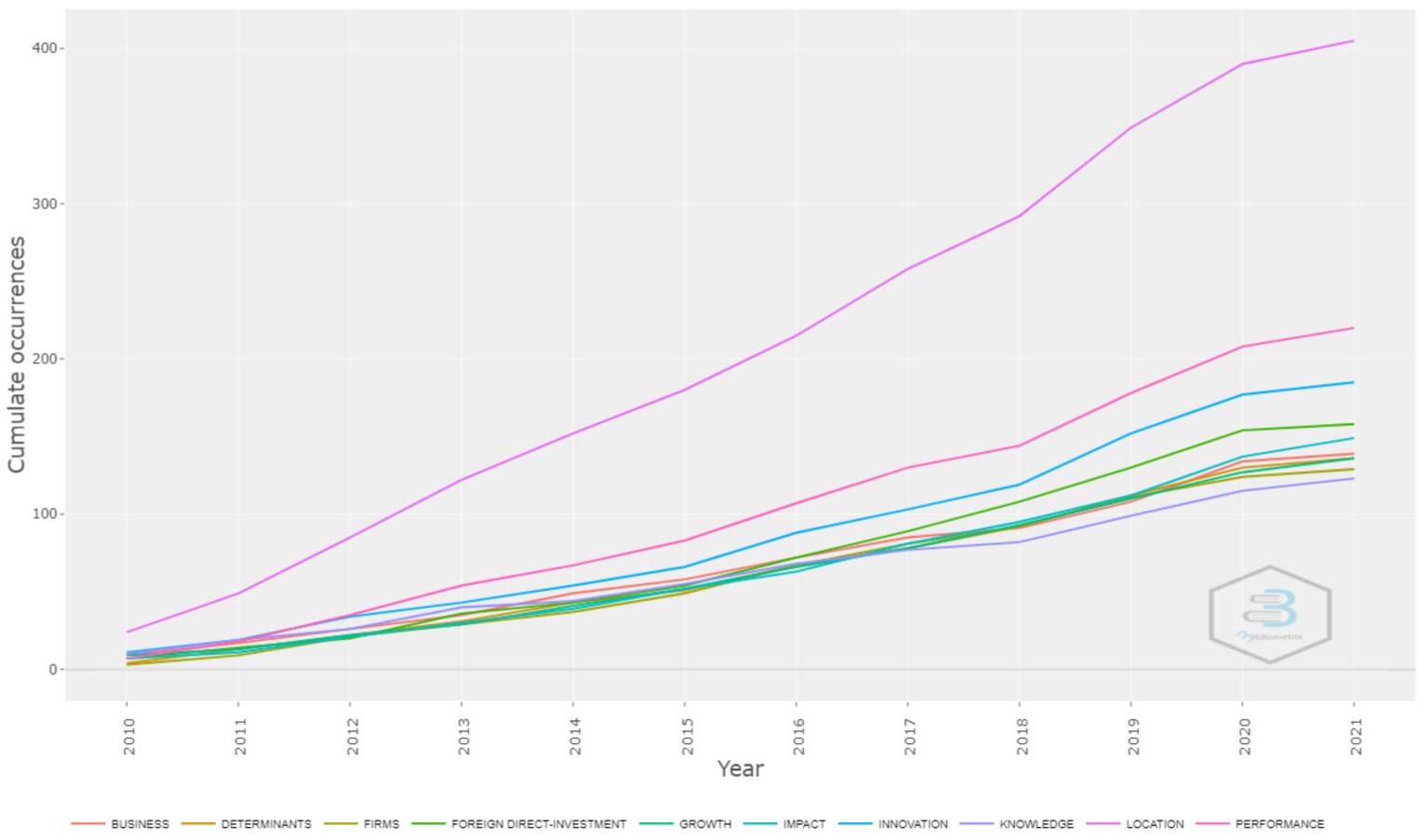

Figure 1. Word Growth.

In other words, we observe that there is a direct connection, in the first cluster, between the 'location' and the 'agglomeration', 'growth', 'geography', 'city' and 'policies'. At the same time, in the second dominant cluster, we observe the connections between 
performance and the impact and management of businesses; in the third, the connection between foreign direct investment and location choice, strategies and determinants; and in the fourth, the connection between innovation/knowledge, research and development and firm performance/productivity. These connections (especially in the first dominant cluster) are what motivates and verifies the aim of this article.

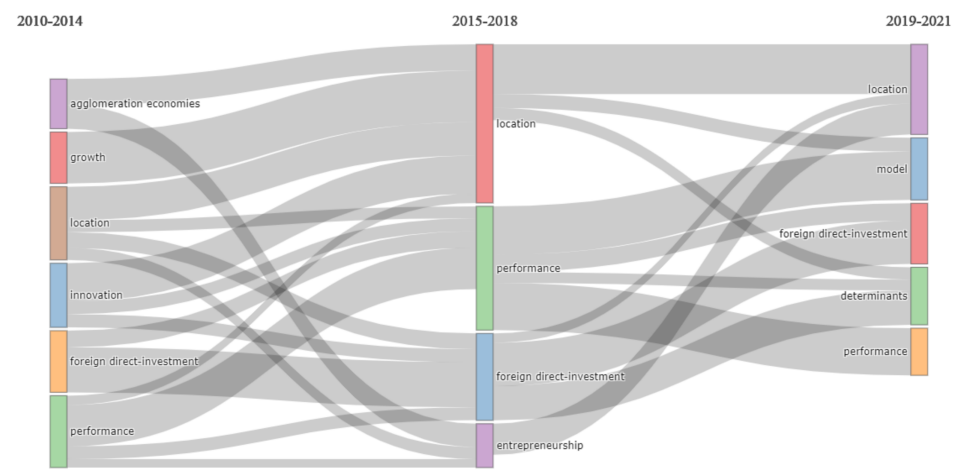

Figure 2. Thematic Evolution.

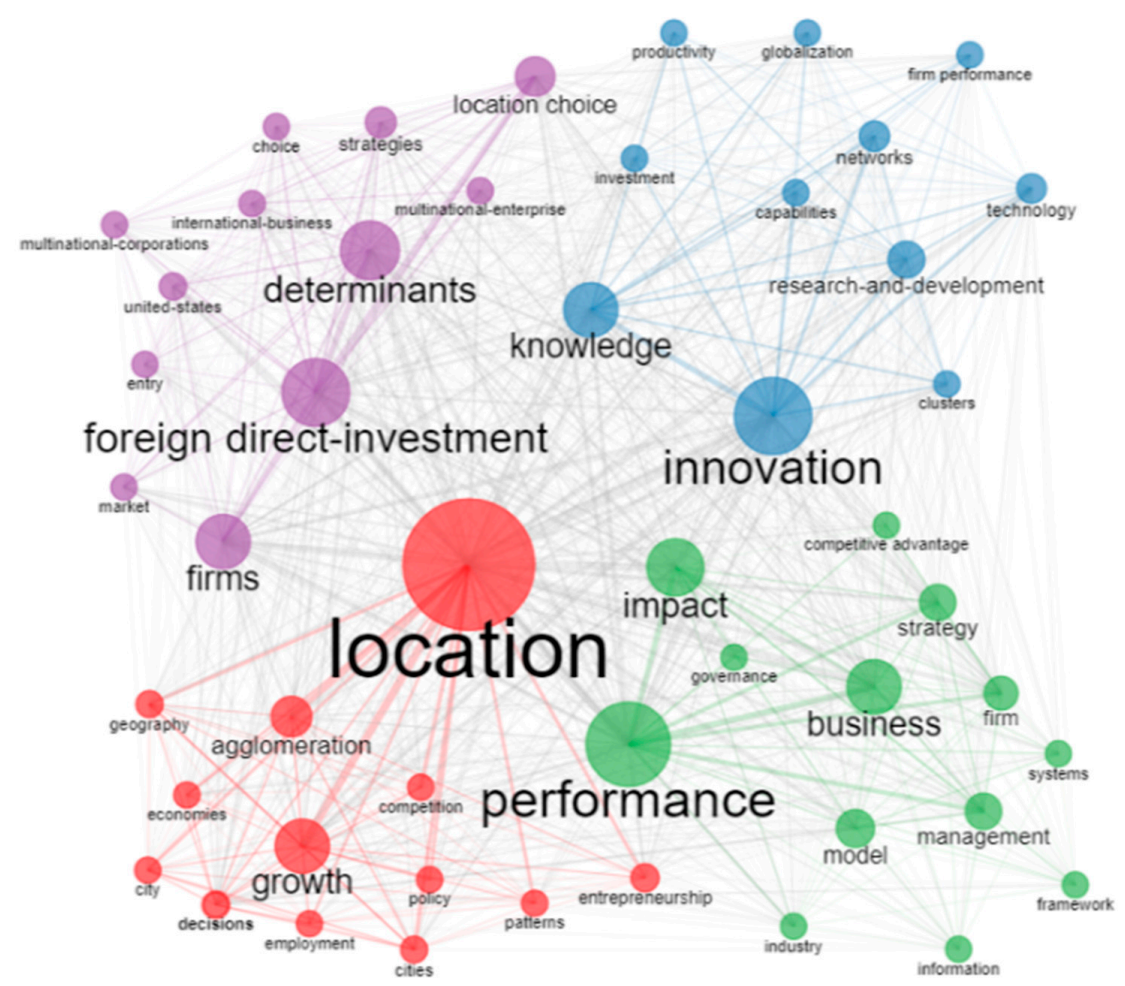

Figure 3. Co-occurrence network.

\section{Methodology, Data, Sources, and Study Area}

The study was conducted in the city of Volos (Greece), which was selected due to the following traits:

- First, on the one hand, Volos concentrates a variety of economic branches (Figure 4), and, on the other hand, due to the economic crisis, Volos, as with other Greek cities, experienced the phenomenon of shrinking cities, with many businesses closing, resulting in many vacant shops and abandoned office buildings (especially in the peri-urban area and less central city units) and a reduction in per capita gross domestic product (Figure 5)

- Second, Volos has an average population size compared to the Greek data, with a permanent population equal to 86,046, while the entire Urban Complex of Volos 
(including Nea Ionia) amounts to 118,707 inhabitants, according to the 2011 census; the city thus represents the largest population size among Greek cities, except for Athens, Thessaloniki, and Piraeus.

- Third, Volos is characterized by the typical morphology (e.g. streets, squares, building blocks) of modern Greek cities.

- Fourth, the city boasts several public universities (such as the University of Thessaly) and private research institutions.

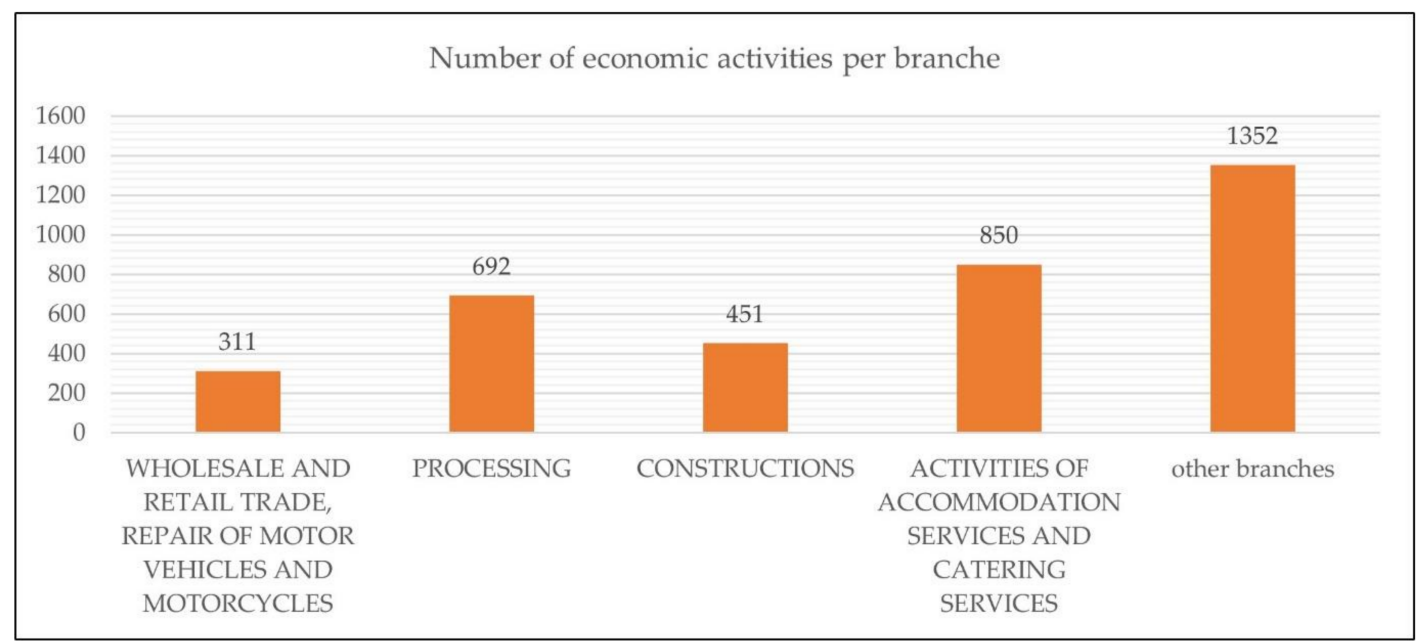

Figure 4. Number of economic activities per branch. Source: Chamber of Magnesia; own editing.

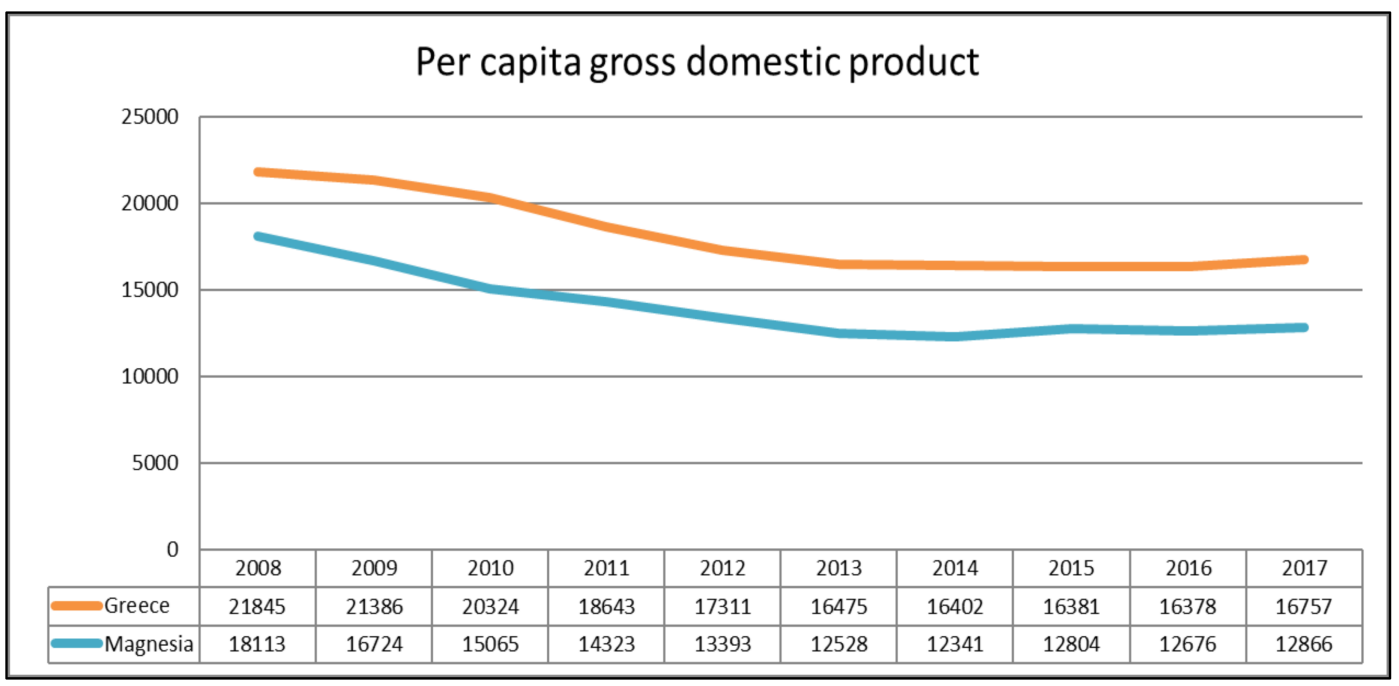

Figure 5. Per capita gross domestic product. Source: Chamber of Magnesia; own editing.

Our data come from the Chamber of Volos and the Hellenic Statistical Authority (EL.STAT.). The data from the Chamber of Volos concern companies that were based in the settlement of Volos during the period from 1 January 2014 to 31 December 2019. The year 2015 was selected because the signs of economic crisis seem to have remained stable during this period, according to Figure 5.

The categorization of land use data was based on the general urban plan of Volos. The database created the appropriate digital backgrounds (road axis and urban blocks) and point databases. The procedure followed was geocoding, whereby the desired cartographic data were produced using information describing sites such as postal addresses and address locators. Through this process, most of the businesses immediately acquired 
spatial reporting. Other businesses were manually matched with the help of location programs such as Google Maps and Google Earth [24].

\subsection{Calculation of Unoccupied/Occupied Business Premises}

The research started with the calculation of unoccupied/occupied business premises per building block during the aforementioned study period (2015-2019). At the first stage, the research identified urban units in adjacent urban blocks in Volos with similar characteristics that present a high percentage of unoccupied buildings, indicating their vulnerability to spatial and economic shrinkage. The research continued with the identification of areas within Volos that presented an increased frequency of new recordings over the period under consideration. Based on this analysis, the research identified not only the spatial distribution of the percentage per building block but also the spatial patterns, that is, spatial units consisting of urban blocks [24]. Moreover, with the identification of the percentages of unoccupied and occupied businesses, we can use them as spaces to implement the model to decide the optimal business location for every economic activity.

\subsection{Optimal Selection of Business Location}

At this stage of the research, some assumptions were made in order to draw valid conclusions. First, four branches of economic activities were selected (Table 3 ) because they reflect $63 \%$ of all economic activities in the city of Volos and, for this reason, they contribute significantly to the economic development of the city (Figure 4).

Table 3. Categorization by STAKOD.

\begin{tabular}{cc}
\hline \multicolumn{2}{c}{ Branches } \\
\hline Sectors & Name \\
\hline A & Processing \\
\hline B & Construction \\
\hline C & Wholesale and retail trade, repair or motor vehicles and motorcycles \\
\hline D & Activities of accommodation services and catering services \\
\hline
\end{tabular}

Second, the year 2015 was selected to identify the optimal business location of the economic activities because the signs of economic crisis seem to have remained stable during this period according to the following chart. Furthermore, it can be verified whether the model works by monitoring the companies that opened in 2015 and did not close during the next 4 years (2015-2019).

Third, in order to detect the optimal area of business activity, certain weights were defined:

a) The location of the economic activity.

b) The number of existing economic activities.

c) The land uses.

To identify the location of the business activity and reduce shrinking cities, all the stores that closed in 2014 were used because they were considered empty stores in 2015. For this reason, they can be used as future business locations. The number of existing business activities are the businesses that were active in this period and documented in the professional chamber of Volos. Finally, the land uses, as mentioned earlier, are from the General Urban Plan of Volos.

\section{Step 1: Identification of Areas Vulnerable to Urban Shrinkage}

The calculation of the percentage of unoccupied and occupied business premises does not demonstrate significant variation during the study period. The application of the model per building block, according to Figures 6 and 7, shows the importance of the commercial center of the city of Volos as well as the economic and spatial urban shrinkage of less central areas. Specifically, it is observed from both maps that the areas that are 
most exposed to urban shrinkage are the least central areas (i.e., Anakasia, Neapoli Agia Paraskevi, and Nea Dimitriada). On the other hand, the shopping center of the city, despite the large percentage of closed stores (as shown in Figure 6), continues due to its centrality in terms of attracting more new businesses.

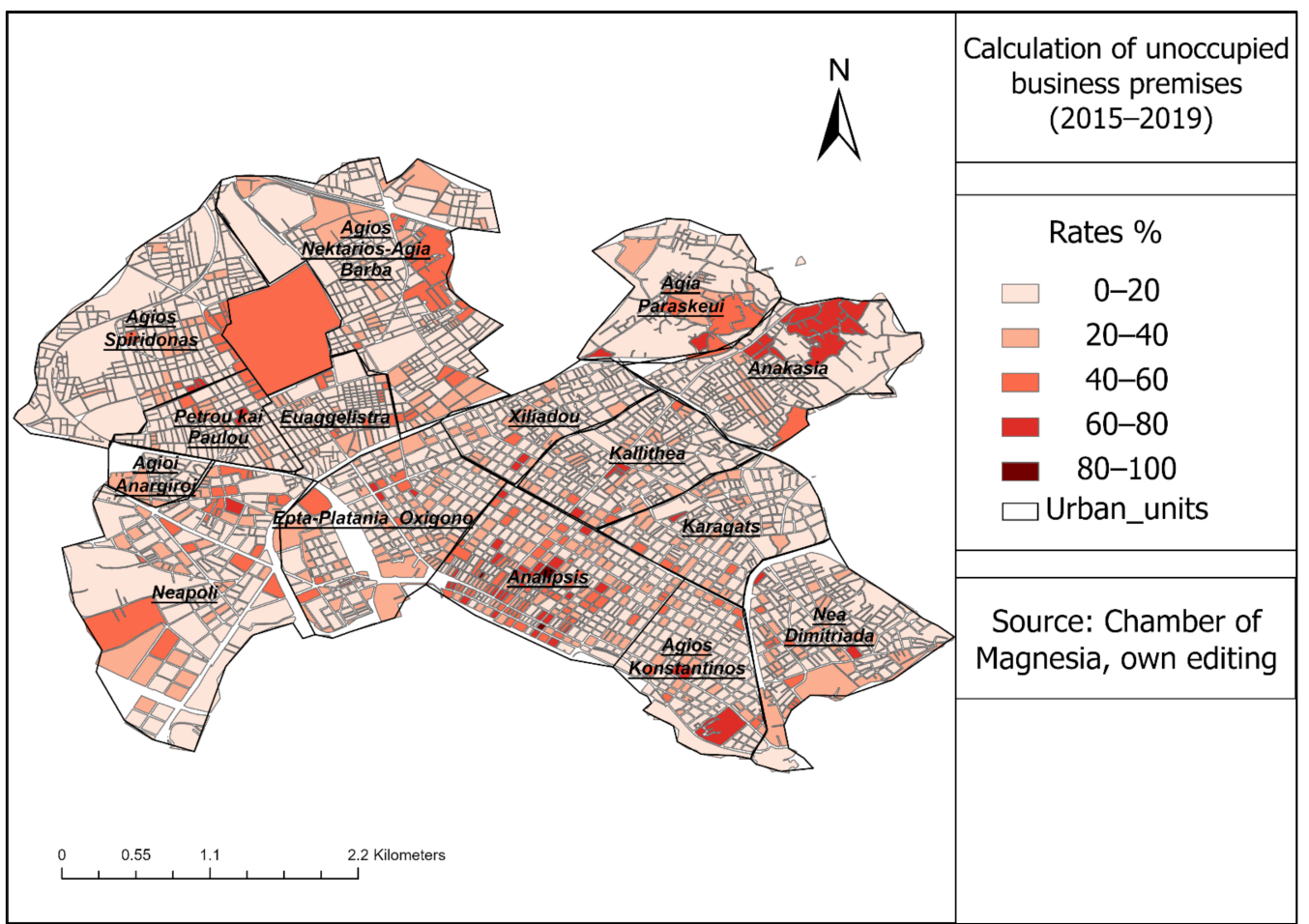

Figure 6. Calculation of unoccupied business premises, 2015-2019.

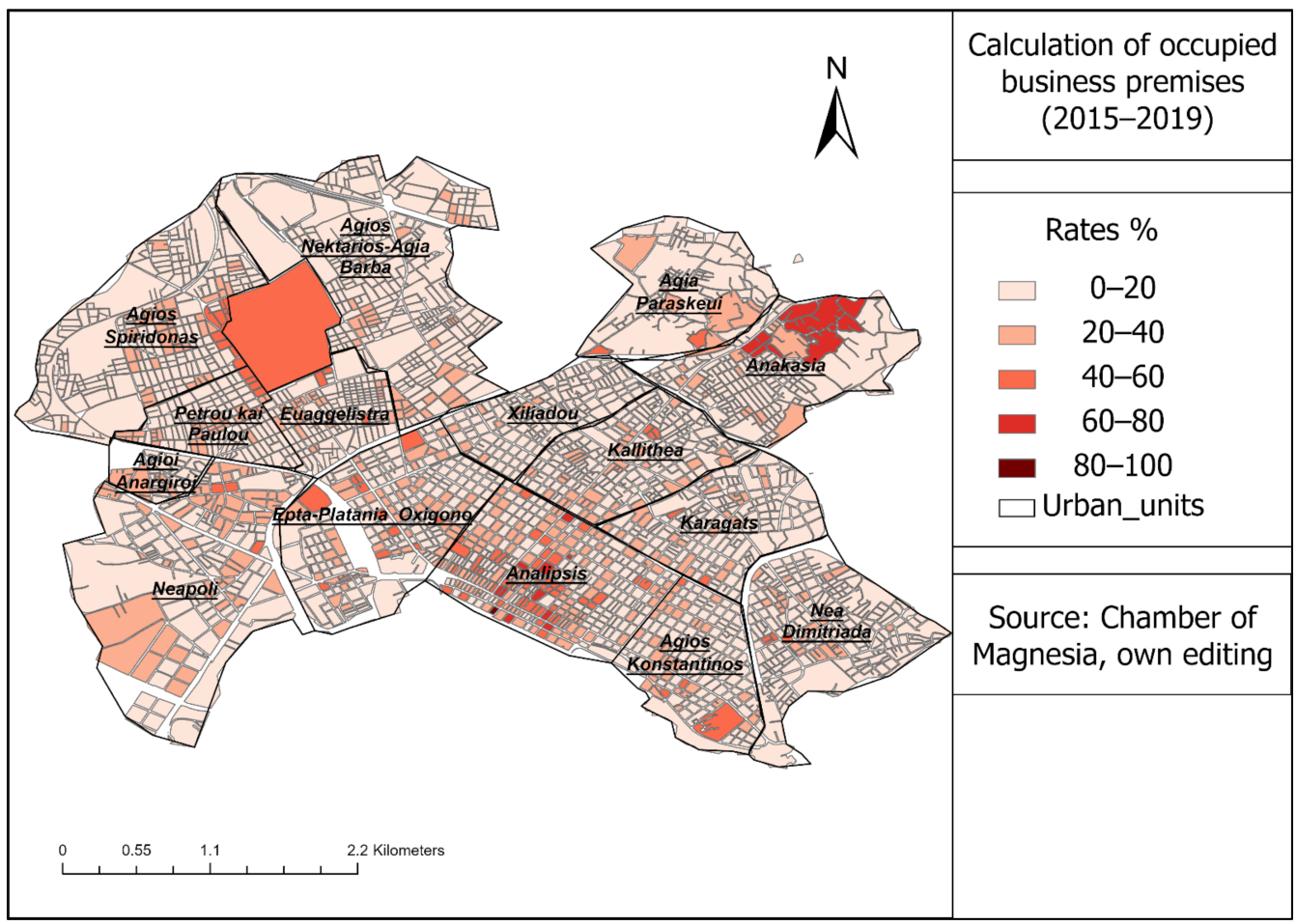

Figure 7. Calculation of occupied business premises, 2015-2019. 
Therefore, it is observed that the less central areas are more vulnerable to the phenomenon of urban shrinkage. For this reason, it is important to identify the optimal locations for the establishment of economic activities, thereby reducing urban shrinkage and increasing the life of businesses.

\section{Step 2: Identification of Business Optimal Location}

The calculation of the optimal location of the economic activity is based on certain weights that determine to what extent the location of the business activity in the specific building block is financially beneficial for it. More specifically:

a) The weight for the wholesale and retail trade, and repair of motor vehicles and motorcycles, assumes that activities that are close to the shopping center benefit more than others that are quite far from it. In addition, the number of existing economic activities in the same area has a negative effect on the financial well-being of the business.

b) In the category of processing, the economic activities that are relatively far from the commercial center of the city and are next to important roads have a significant advantage over others. Moreover, the concentration of companies helps in the creation of concentrated economies, so it contributes significantly to the development of the business.

c) In the construction category, the location of businesses within the shopping center and generally close to existing economic activities is quite important. However, the concentration of the same activities in the construction sector has a negative effect.

d) The last branch is the activities of accommodation services and catering services, which benefit significantly when they are close to the shopping center as well as when there is a large concentration of services in the same sector. Finally, land uses have a positive effect where economic activities are allowed.

\section{Results}

According to the above, it is observed in Figure 8 that the areas where the wholesale and retail trade sector is favored are in the commercial center of the city (Analipsis), while the areas where it is located nearby are indicated for this economic activity. Moreover, Figure 9 shows the wholesale and retail businesses that opened in 2015, and which did not close for the next 4 years. Comparing these two figures, it is concluded that the weights of the model for estimating the best location of economic activity are quite close to reality, making it a useful tool for the analysis and identification of optimal areas for the placement of economic activities.

Regarding the processing branch, the optimal locations (Figures 10 and 11) of the economic activities are placed in both the shopping center (Analipsis) of the city (because several businesses closed last year and there are many vacant stores) as well as in the suburbs of the city where there are already many processing economic activities.

In the sector of catering and accommodation services (Figures 12 and 13), there is a large concentration both in the shopping center (Analipsis) of the city and in building blocks near the port due to the need to concentrate them on shopping streets and in areas with views. This can be seen more clearly in the heat map (Figure 13), where the businesses that opened in $2015 \mathrm{did}$ not close in these areas, showing the importance they have.

In the construction sector (Figures 14 and 15), there is an intense concentration of optimal areas in the shopping center (Analipsis) of the city and in urban units bordering the center (Kalithea, Epta-Platania-Oxigono, and Agios Konstantinos). On the other hand, as shown in Figure 15, there is a large concentration at the border of the shopping center with the urban unit of Kalithea, thus showing that there is quite a high accuracy between the model and reality. 


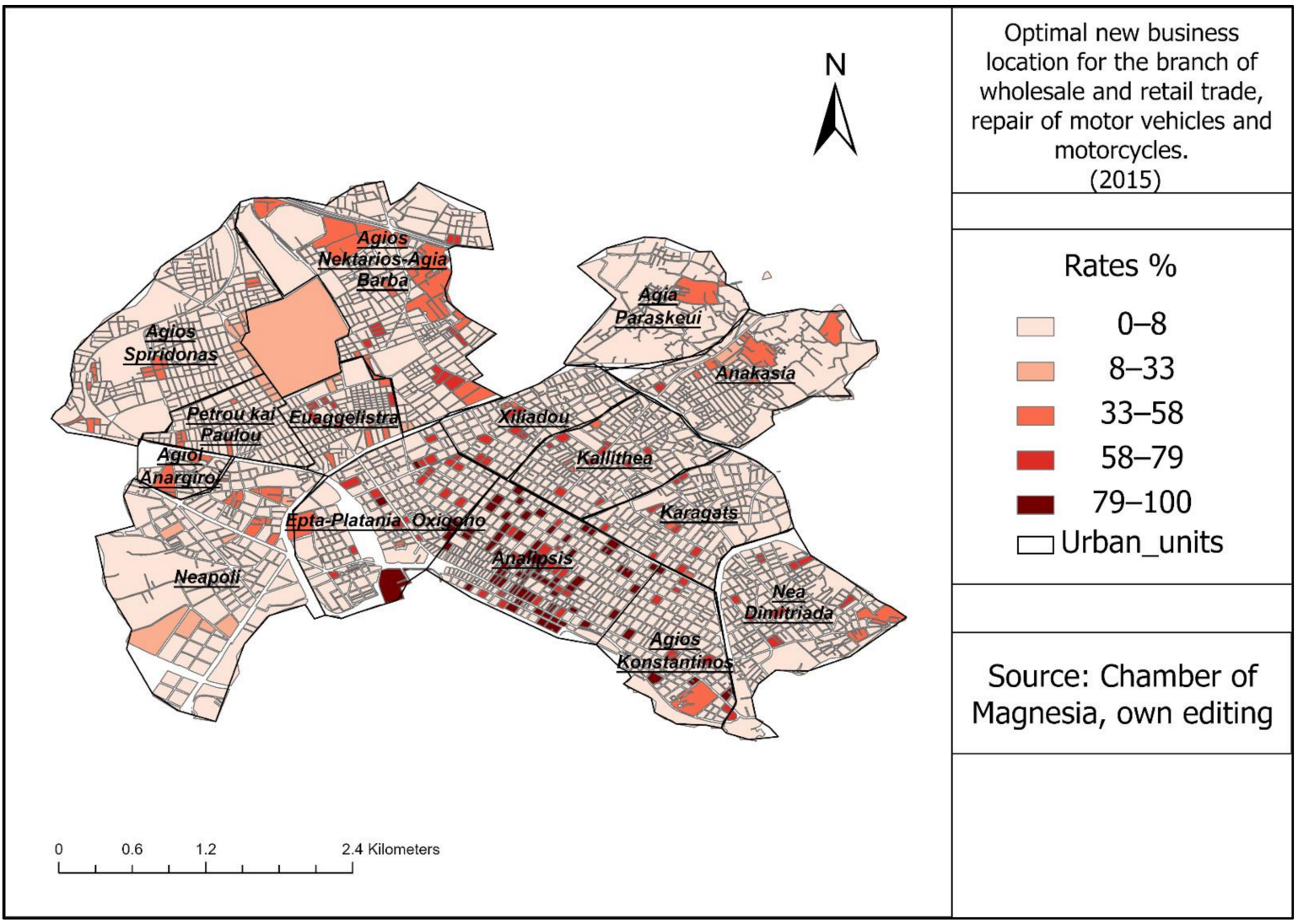

Figure 8. Optimal new business location for the wholesale and retail trade branches, 2015.

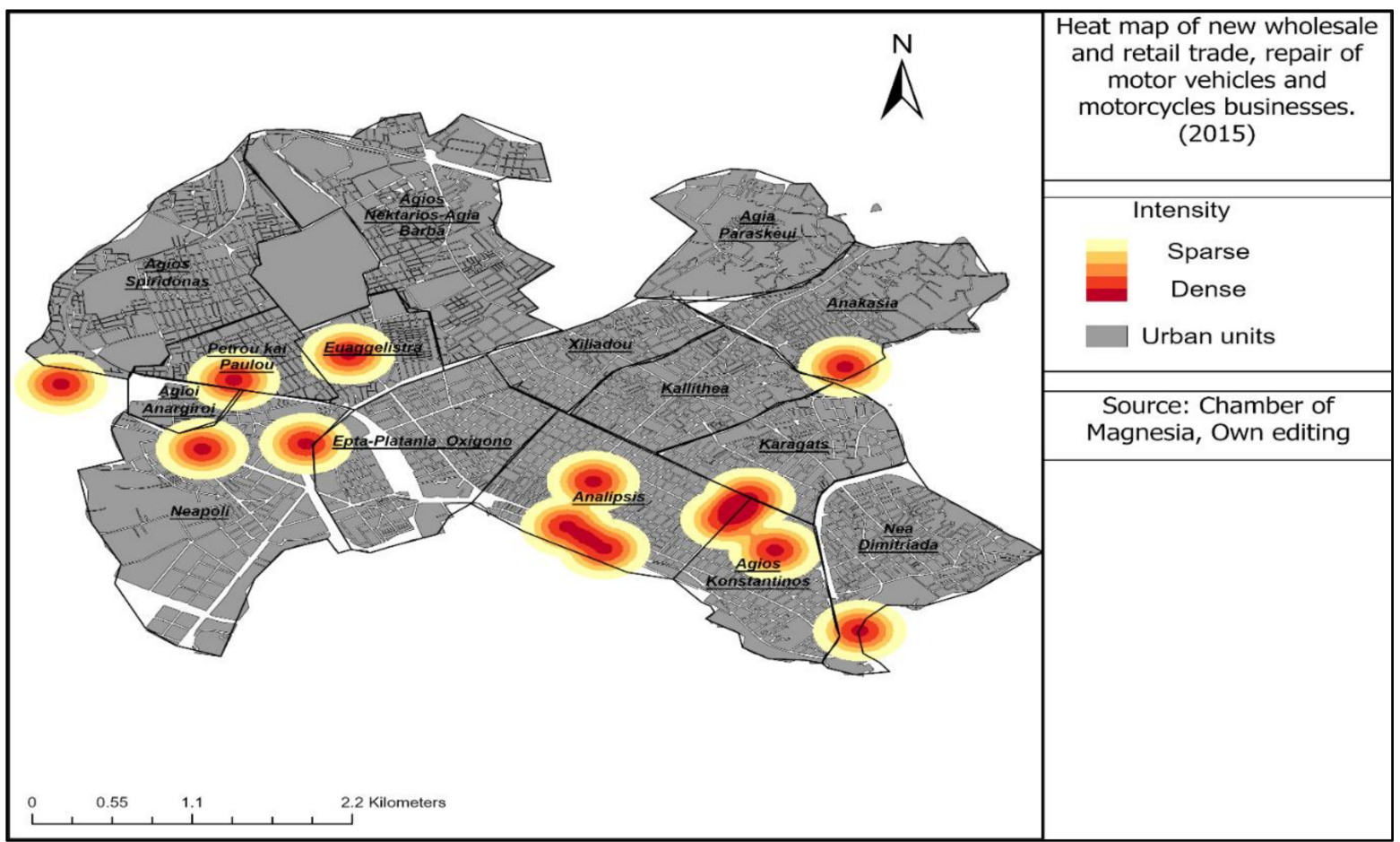

Figure 9. Heat map of new wholesale and retail trade businesses, 2015. 


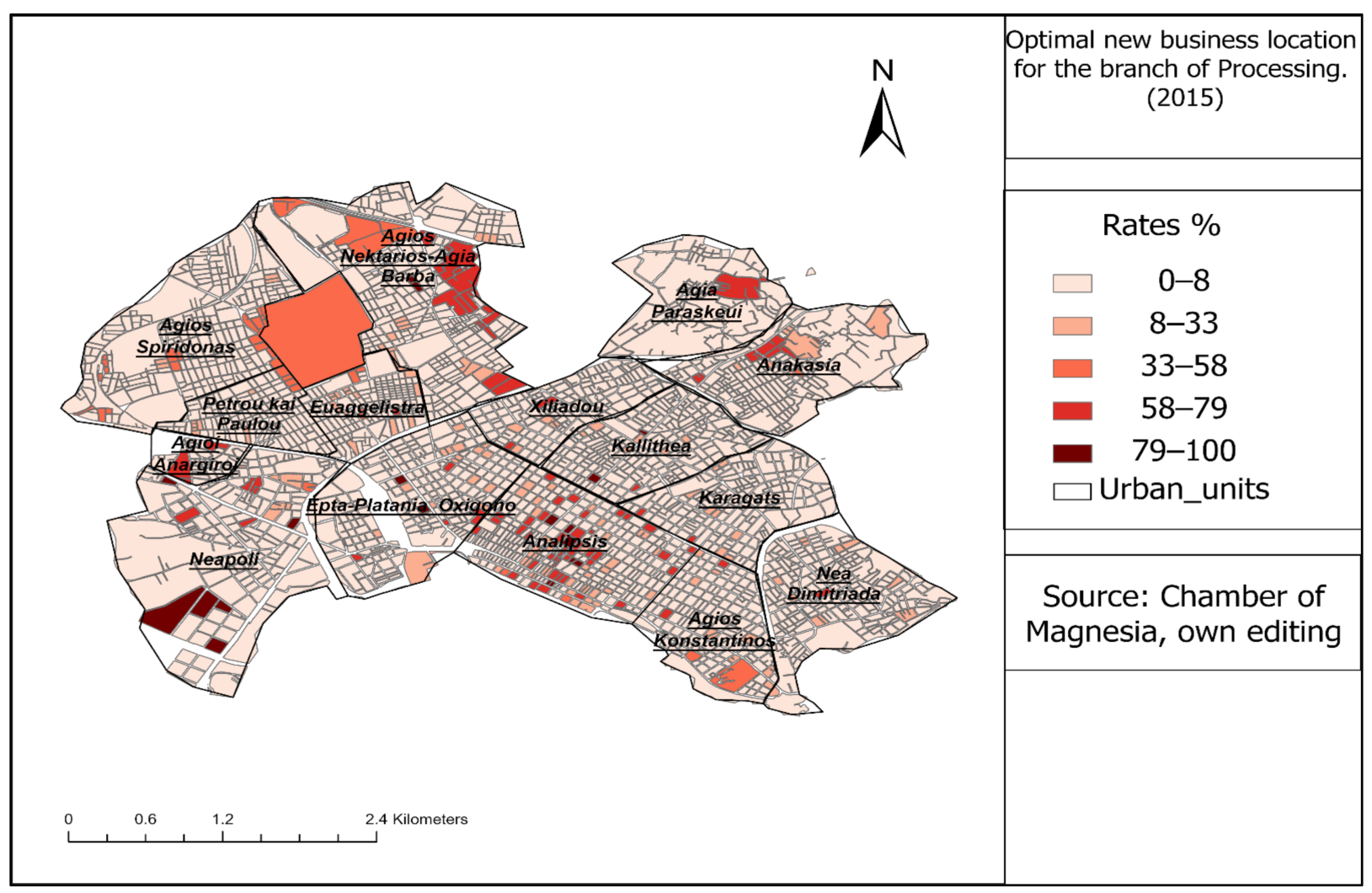

Figure 10. Optimal new business location for the Processing branch, 2015.

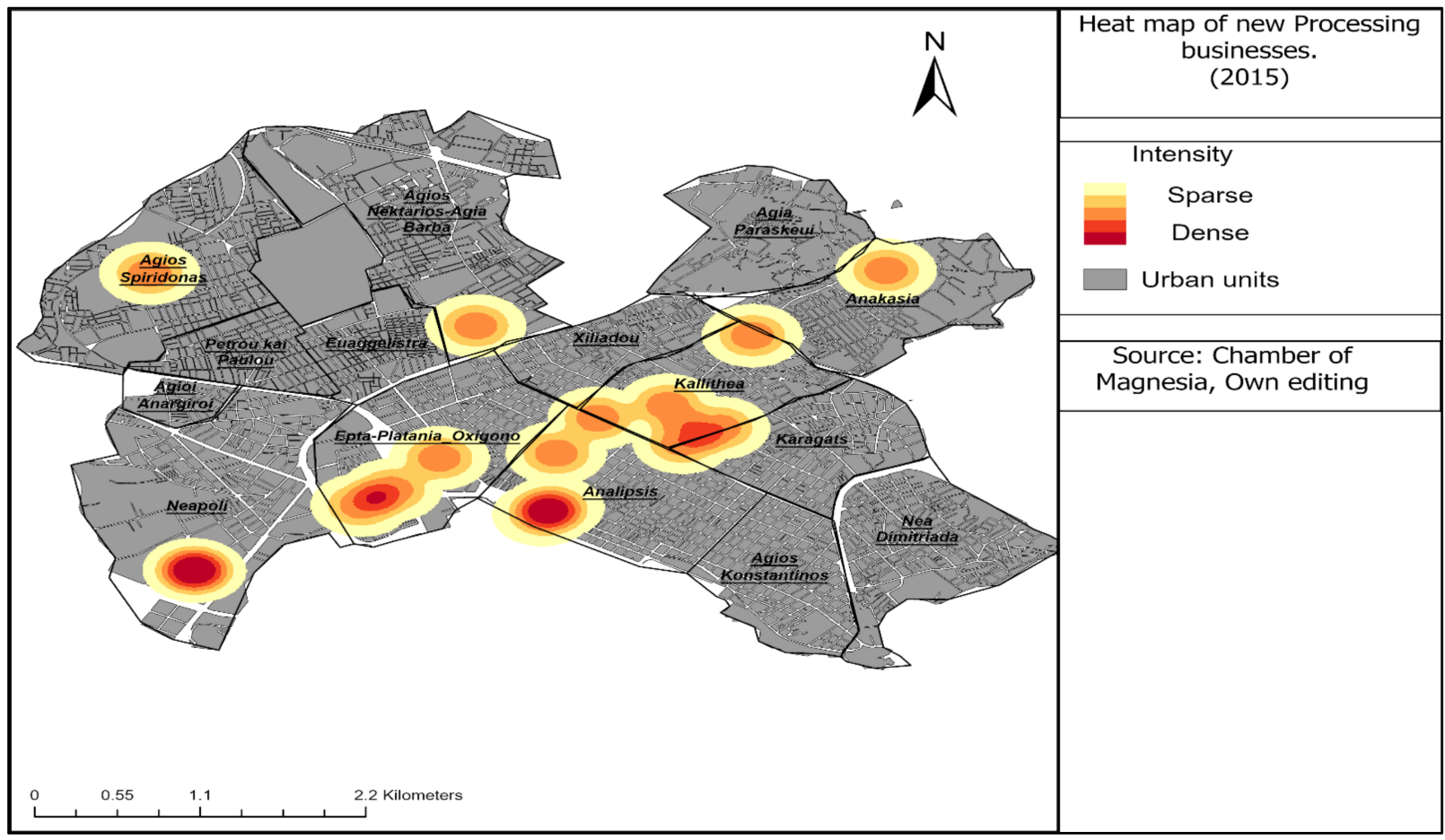

Figure 11. Heat map of new Processing businesses, 2015. 


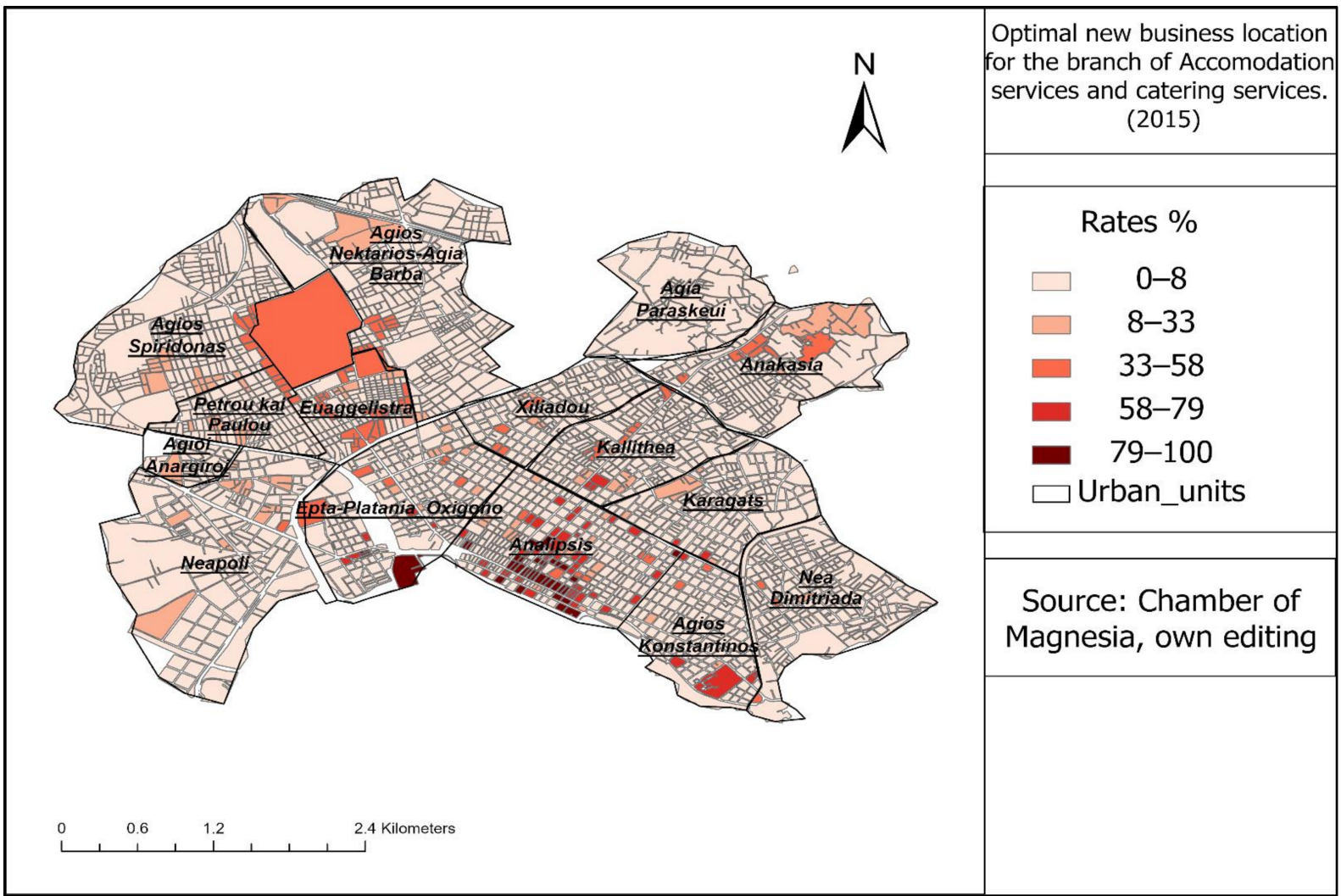

Figure 12. Optimal new business location for the Accommodation services and Catering services branches, 2015.

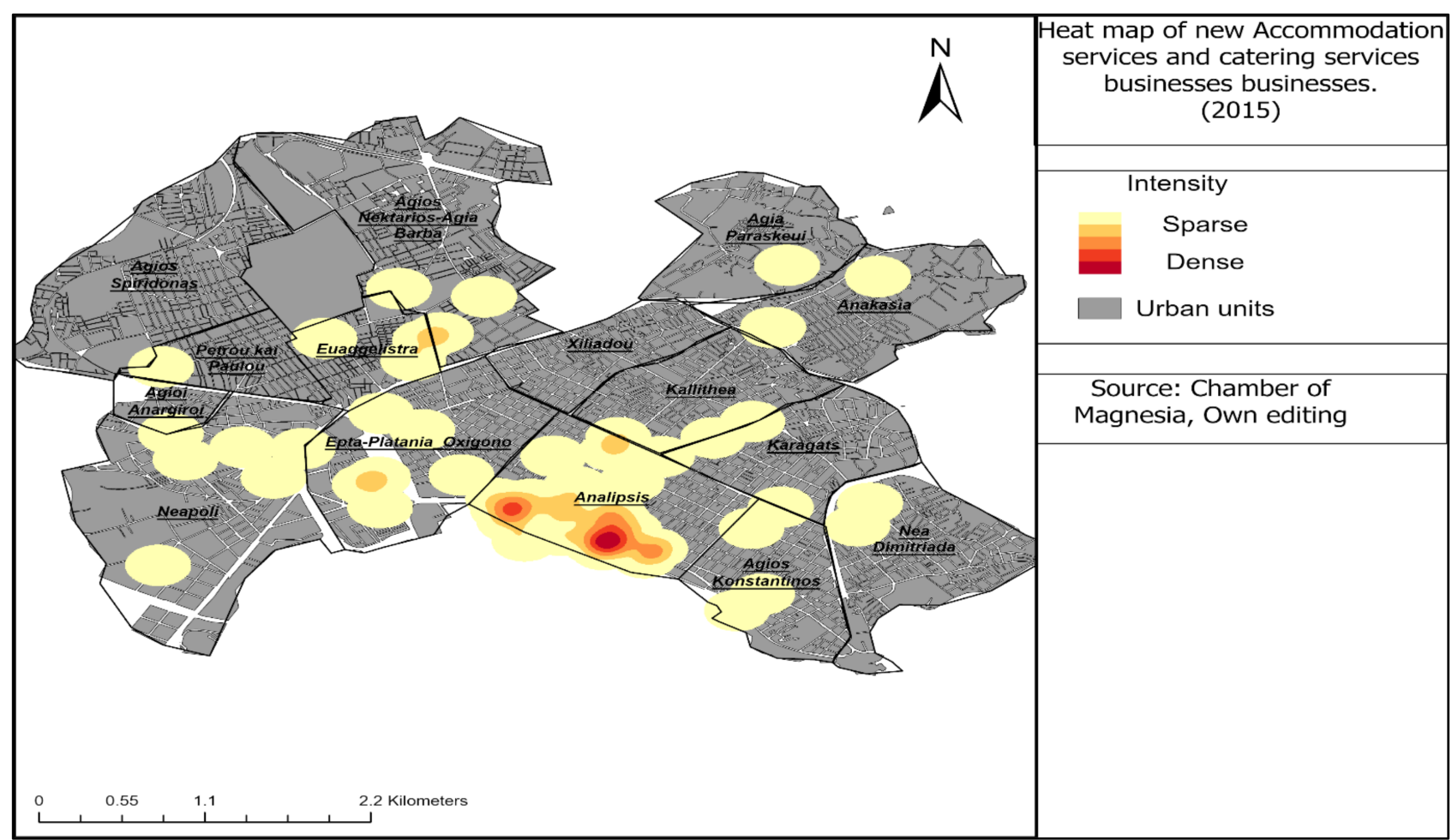

Figure 13. Heat map of new Accommodation service and Catering service businesses, 2015. 


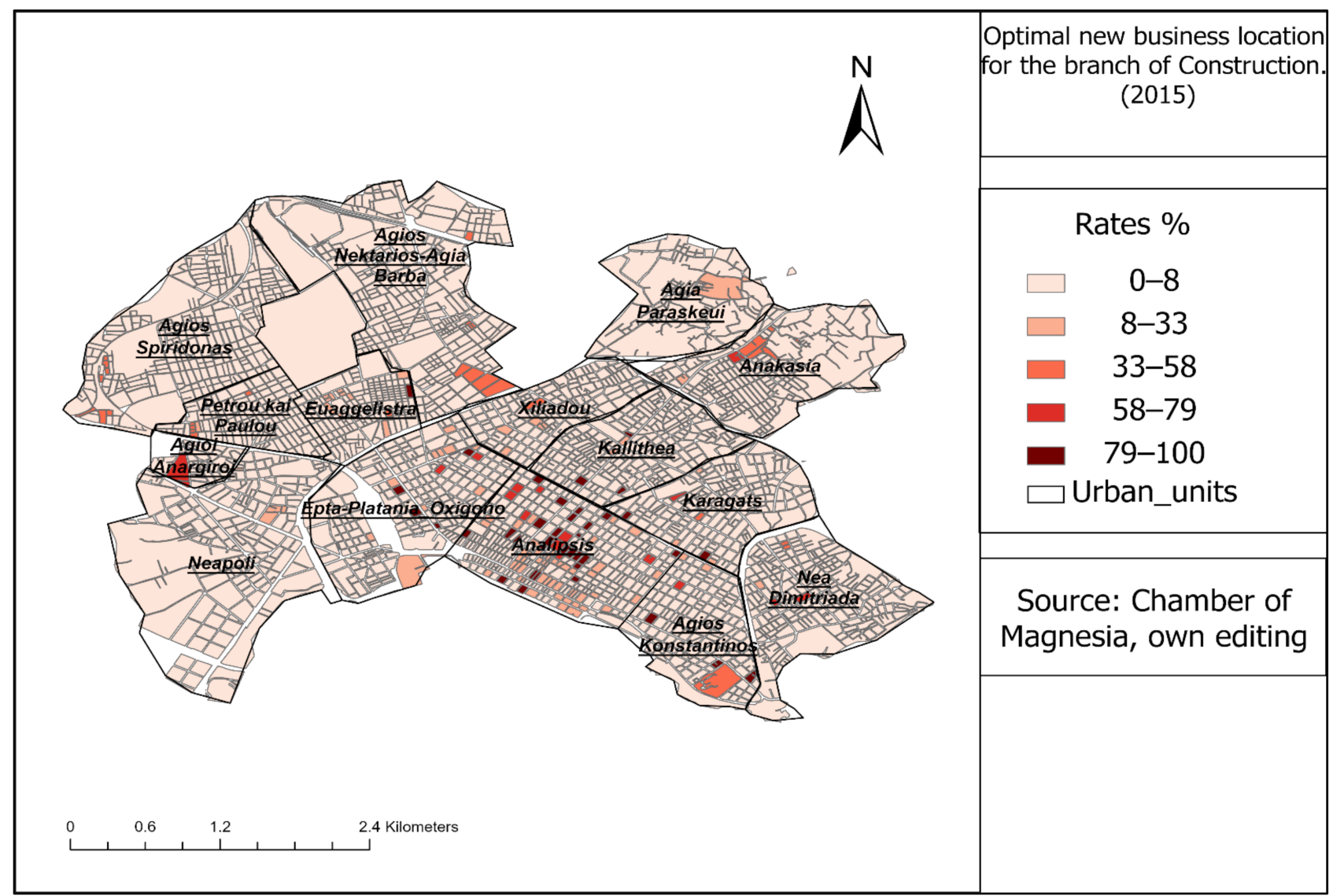

Figure 14. Optimal new business location for the Construction branch, 2015.

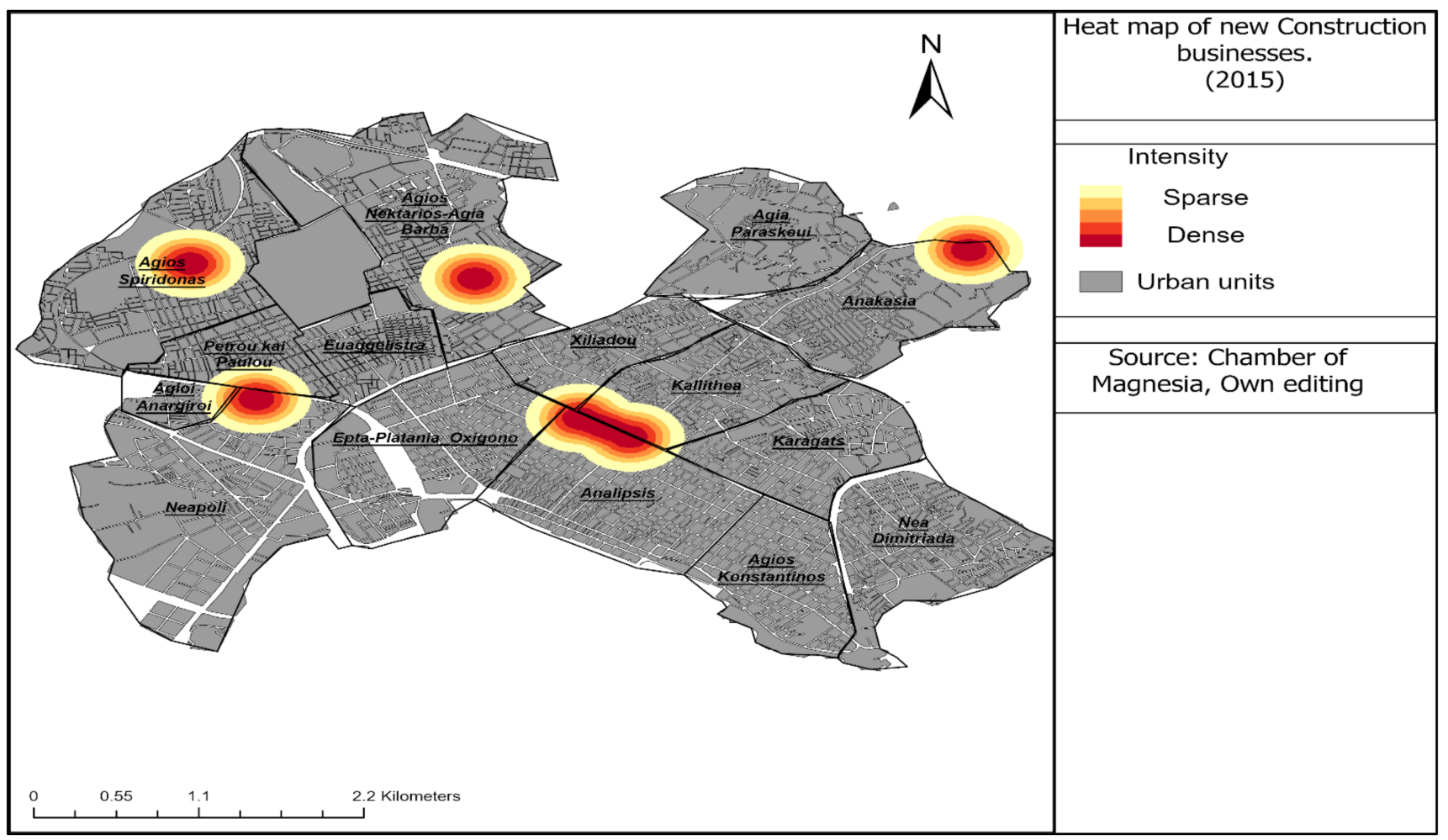

Figure 15. Heat map of new Construction businesses, 2015. 


\section{Discussion}

Location theory has long been a central component of economic geography and urban studies, involving part explanation and part prediction regarding the location and interaction of people, goods, and services in both the private and public sectors. Location theory is the basis and/or context for studying how and why location decisions are made, whether by companies, government agencies, or people; it also provides the rationale for siting decision-making and service allocation. Classic works in this field have focused explicitly on land use and transportation costs, primarily in product manufacturing and delivery. More recent work on location theory builds upon this but has also been broadened to address a range of issues, including assumptions made, model abstraction, and computational complexity [25]. The analysis of this paper, based on a medium-sized Greek city, and viewed through the prism of the assumptions made herein, proved that the areas that are most exposed to urban shrinkage are the least central areas. On the other hand, the shopping center of the city, despite the large percentage of closed stores, continues due to its centrality to attracting more new businesses. For this reason, it is considered appropriate to identify the optimal locations for the establishment of economic activities, thereby reducing urban shrinkage and increasing the life of businesses. The calculation of the optimal location of the economic activity was based on certain weights that determine to what extent the location of the business activity in the specific building block is financially beneficial for it, and it showed that the optimal location depends on the financial sector itself but also on the economic activities that open or close over time in this region. The optimal location method is a method that has been used in a variety of current prior research, such as location selection for new economic businesses, trade evaluation areas or business location prediction and planning. The way in which the optimal location was applied in this article creates new perspectives in the study of urban shrinkage as it can more efficiently prove the individual interactions of economic activities. In this manner, an answer is sought regarding the way in which each region and its economic identity can influence a city's future development and resilience.

\section{Conclusions}

With the view to achieving resilience of cities, it is important that the policies adopted refer to both the urban and local scales. In order to increase the efficiency and effectiveness of businesses, it is necessary to first recognize the most vulnerable urban areas and then move forward with smart solutions by taking into consideration the individual characteristics of each area [1].

Initially, the detection of vulnerable areas is the first step, as applied in this paper, for the better organization of economic activities and, consequently, the economy of the city. Second, finding optimal areas for the establishment of economic activities is an important factor in dealing with urban shrinkage as well as in developing the right policies, to ensure that they will act as positive and not as negative factors for businesses. These locations, as identified, can become levers for the development of the economic strength and resilience of the city as it is the area that can most affect the current and future financial strength of the city. In addition, the identification of optimal areas of economic activity can significantly contribute to young entrepreneurs who do not know the economic profile of the city and are trying to settle in its market.

Finally, in finding optimal areas of economic activity, current technological progress and the development of society cannot be omitted. Today, new factors are emerging that are related to the development of businesses and the ways in which they operate. For this reason, the best location for a business is related not only to spatial factors but also to intangible (Internet-related) factors that promote its operation and help it to grow.

Author Contributions: Conceptualization, S.M., K.K. and A.G.; Data curation, K.K.; Formal analysis, S.M. and K.K.; Investigation, S.M. and K.K.; Methodology, S.M., K.K. and A.G.; Resources, S.M., K.K. and A.G.; Software, S.M. and K.K.; Validation, K.K.; Visualization, S.M. and K.K.; Writing-original 
draft, S.M. and K.K.; Writing-review and editing, S.M., K.K. and A.G. All authors have read and agreed to the published version of the manuscript.

Funding: This research received no external funding.

Institutional Review Board Statement: Not applicable.

Informed Consent Statement: Not applicable.

Conflicts of Interest: The authors declare no conflict of interest.

\section{References}

1. Manika, S. Transforming vacant commercial spaces: From localized hotspots of urban shrinkage to 'smart' co-working places. Open J. Soc. Sci. 2020, 8, 86-97. [CrossRef]

2. Batty, M. The size, scale, and shape of cities. Science 2008, 319, 769-771. [CrossRef] [PubMed]

3. Meerow, S.; Newell, J.P.; Stults, M. Defining urban resilience: A review. Landsc. Urban Plan. 2016, 147, 38-49. [CrossRef]

4. Brand, F.S.; Jax, K. Focusing the meaning(s) of resilience: Resilience as a descriptive concept and a boundary object. Ecol. Soc. 2007, 12, 23. [CrossRef]

5. Zeng, Q.; Zhong, M.; Zhu, Y.; Li, J. Business Location Selection Based on Geo-Social Networks. Available online: https: / /link.springer.com/chapter/10.1007/978-3-030-59419-0_3 (accessed on 5 September 2021).

6. Zeng, Q.; Zhong, M.; Zhu, Y.; Qian, T.; Li, J. Business location planning based on a novel geo-social influence diffusion model. Inf. Sci. 2021, 559, 61-74. [CrossRef]

7. Taniar, D.; Safar, M.; Tran, Q.T.; Rahayu, W.; Park, J.H. Spatial Network RNN Queries in GIS. Comput. J. 2011, 54, 617-627. Available online: https:/ /academic.oup.com/comjnl/article/54/4/617/357964 (accessed on 1 September 2021).

8. Kempe, D.; Kleinberg, J.; Tardos, E. Maximizing the spread of influence through a social network. In Proceedings of the KDD03: The Ninth ACM SIGKDD International Conference on Knowledge Discovery and Data Mining, Washington, DC, USA, 24-27 August 2003; pp. 137-146.

9. Shi, J. Relationship between maximum principle and dynamic programming for stochastic differential games of jump diffusions. Int. J. Control 2013, 87, 693-703. [CrossRef]

10. Hung, H.J.; Yang, D.N.; Lee, W.C. Social influence-aware reverse nearest neighbor search. ACM Trans. Spat. Algorithms Syst. 2016, 2, 1-35. Available online: https: / dl.acm.org/doi/abs/10.1145/2964906 (accessed on 5 September 2021). [CrossRef]

11. Chang, X.; Li, J. Business performance prediction in location-based social commerce. Expert Syst. Appl. 2019, 126, 112-123. [CrossRef]

12. P, A.K.; G, S.S.; Maddikunta, P.K.R.; Gadekallu, T.R.; Al-Ahmari, A.; Abidi, M.H. Location Based Business Recommendation Using Spatial Demand. Sustainability 2020, 12, 4124. Available online: https:/ /www.mdpi.com/2071-1050/12/10/4124/htm (accessed on 2 September 2021). [CrossRef]

13. McKenzie, G.; Adams, B. Juxtaposing Thematic Regions Derived from Spatial and Platial User-Generated Content. In Proceedings of the 13th International Conference on Spatial Information Theory (COSIT 2017), L'Aquila, Italy, 5-8 September 2017.

14. Liang, Y.; Gao, S.; Cai, Y.; Foutz, N.Z.; Wu, L. Calibrating the dynamic Huff model for business analysis using location big data. Trans. GIS. 2020, 24, 681-703. [CrossRef]

15. Liu, T. Combining GIS and the Huff Model to Analyze Suitable Locations for a New Asian Supermarket in the Minneapolis and St. Paul, Minnesota USA. Pap. Resour. Anal. 2012, 14, 7.

16. Pan, H.; Li, Y.; Dang, A. Application of network Huff model for commercial network planning at suburban-Taking Wujin district, Changzhou as a case. Ann. GIS. 2013, 19, 131-141. [CrossRef]

17. Grohmann, S.; Urošević, D.; Carrizosa, E.; Mladenović, N. Solving multifacility Huff location models on networks using metaheuristic and exact approaches. Comput. Oper. Res. 2017, 78, 537-546. [CrossRef]

18. Wang, Y.; Jiang, W.; Liu, S.; Ye, X.; Wang, T. Evaluating trade areas using social media data with a calibrated huff model. ISPRS Int. J. Geo-Information 2016, 5, 112. [CrossRef]

19. Banerjee, S.; Kabir, M.M.; Khadem, N.K.; Chavis, C. Optimal locations for bikeshare stations: A new GIS based spatial approach. Transp. Res. Interdiscip. Perspect. 2020, 4, 100101. [CrossRef]

20. Aria, M.; Cuccurullo, C. bibliometrix: An R-tool for comprehensive science mapping analysis. J. Informetr. 2017, 11, 959-975. [CrossRef]

21. Aria, M.; Misuraca, M.; Spano, M. Mapping the evolution of social research and data science on 30 years of social indicators research. Soc. Indic. Res. 2020, 149, 803-831. [CrossRef]

22. Palumbo, R.; Manesh, M.F.; Pellegrini, M.M.; Caputo, A.; Flamini, G. Organizing a sustainable smart urban ecosystem: Perspectives and insights from a bibliometric analysis and literature review. J. Clean. Prod. 2021, 297, 126622. [CrossRef]

23. Anastasiou, E.; Manika, S.; Ragazou, K.; Katsios, I. Territorial and human geography challenges: How can smart villages support rural development and population inclusion? Soc. Sci. 2021, 10, 193. Available online: https:/ /www.mdpi.com/2076-0760/10/6/193/htm (accessed on 5 September 2021). [CrossRef]

24. Manika, S. Portraying and analysing urban shrinkage in greek cities-The case of Larissa. Curr. Urban Stud. 2020, 8, 284-304. Available online: http:/ / www.scirp.org/journal/PaperInformation.aspx?PaperID=100698 (accessed on 5 September 2021). [CrossRef]

25. Murray, A.T. Location Theory. Int. Encycl. Hum. Geogr. 2009, 270-276. Available online: https://www.sciencedirect.com/science/article/ pii/B9780080449104002029 (accessed on 2 September 2021). 